\title{
CLASSIFIED CONSTRUCTION OF GENERALIZED FURUTA TYPE OPERATOR FUNCTIONS
}

\author{
JiANGTAO YUAN AND ZONGSHENG GAO
}

\begin{abstract}
A kind of construction of generalized Furuta type operator functions $F_{p, t, q}(r, s)=$ $A^{-r / 2}\left(A^{r / 2}\left(A^{t / 2} B^{p} A^{t / 2}\right)^{s} A^{r / 2}\right)^{(q+r) /((p+t) s+r)} A^{-r / 2}$ is introduced. It is based on the classification of the functions $F_{p, t, q}(r, s)$ according to the existence of Furuta inequality. It is showed that all such functions before can be generated by this construction and some of them are sharpened. Also, characterizations of operator order $A \geqslant B \geqslant 0$ and chaotic order $\log A \geqslant \log B$ are obtained which extend the related results before.
\end{abstract}

Mathematics subject classification (2000): 47A63, 47B15.

Key words and phrases: Positive operator, Furuta inequality, operator functions.

\section{REFERENCES}

[1] A. ALuTHGe, On $p$-hyponormal operators for $0<p<1$, Integral Equations Operator Theory, 13 (1990), 307-315.

[2] A. Aluthge And D. WANG, Powers of p -hyponormal operators, J. Inequal. Appl., 3 (1999), 279-284.

[3] T. ANDO, On some operator inequality, Math. Ann., 279 (1987), 157-159.

[4] T. ANDO AND F. HIAI, Log majorization and complementary Golded-Thompson type inequality, Linear Algebra Appl., 197, (1994), 113-131.

[5] M. FUJII, T. FurUtA AND E. KAMEI, Furuta's inequality and its application to Ando's theorem, Linear Algebra Appl., 179 (1993), 161-169.

[6] M. FuJII, T. Furuta AND E. KAMEI, Complements to the Furuta inequality, Proc. Japan Acad. Ser. A Math. Sci., 70 (1994), 239-242.

[7] M. FujII, T. Furuta AND E. KameI, Complements to the Furuta inequality III, Math. Japon., 45 (1997), 25-32.

[8] M. FuJII, J. F. JiAng AND E. KAMEI, Complements to the Furuta inequality IV, Math. Japon., 45 (1997), 511-518.

[9] M. FujII, M. HASHImoto, Y. SEO AND M. YANAGIDA, Characterizations of usual and chaotic order via Furuta and Kantorovich inequalities, Sci. Math., 3 (2000), 405-418.

[10] M. FuJII AND E. KAMEI, Mean theoretic approach to the grand Furuta inequality, Proc. Amer. Math. Soc., 124 (1996), 2751-2756.

[11] M. FuJII, E. KAMEI AND R. NAKAMOTO, On a question of Furuta on chaotic order, Linear Algebra Appl., 341 (2002), 119-127.

[12] M. Funi, E. Kamei And R. NaKamoto, On a question of Furuta on chaotic oreder, II, Math. J. Okayama Univ., 45 (2003), 123-131.

[13] M. FUJI, A. MATSUMOTO AND R. NAKAMOTO, A short proof of the best possibility for the grand Furuta inequality, J. Inequal. Appl., 4 (1999), 339-344.

[14] T. FURUTA, $A \geqslant B \geqslant 0$ assures $\left(B^{r} A^{p} B^{r}\right)^{1 / q} \geqslant B^{\frac{p+2 r}{q}}$ for $r \geqslant 0, p \geqslant 0, q \geqslant 1$ with $(1+2 r) q \geqslant$ $p+2 r$, Proc. Amer. Math. Soc., 101 (1987), 85-88.

[15] T. FuRUTA, Elementary proof of an order preserving inequality, Proc. Japan Acad. Ser. A Math. Sci., 65 (1989), 126.

[16] T. FuRUTA, Two operator functions with monotone property, Proc. Amer. Math. Soc., 111 (1991), 511-516. 
[17] T. FuRUTA, Applications of order preserving operator inequalities, Operator theory: Advances and Applications, 59 (1992), 180-190.

[18] T. FURUTA, Furuta's inequality and its application to the relative operator entropy, J. Operator Theory, 30 (1993), 21-30.

[19] T. FURUTA, Extension of the Furuta inequality and Ando-Hiai log -majorization, Linear Algebra Appl., 219 (1995), 139-155.

[20] T. FuRUTA, Parallelism related to the inequality “ $A \geqslant B \geqslant 0$ ensures $\left(A^{\frac{r}{2}} B^{p} A^{\frac{r}{2}}\right)^{\frac{1+r}{p+r}} \geqslant\left(A^{\frac{r}{2}} A^{p} A^{\frac{r}{2}}\right)^{\frac{1+r}{p+r}}$ for $p \geqslant 1, r \geqslant 0$ ”, Math. Japon., 45 (1997), 203-209.

[21] T. FuRUTA, Parametric operator function via Furuta inequality, Sci. Math., 1 (1998), 1-5.

[22] T. FURUTA, Operator functions involving order preserving inequality, Sci. Math., 1 (1998), 141-147.

[23] T. FURUTA, Simplified proof of an order preserving operator inequality, Proc. Japan Acad. Ser. A Math. Sci., 74 (1998), 114.

[24] T. FURUTA, Results under $\log A \geqslant \log B$ can be derived from ones under $A \geqslant B \geqslant 0$ by Uchiyama's method - associated with Furuta and Kantorvich type operator inequalities, Math. Inequal. Appl., 3 (2000), 423-436.

[25] T. FurutA, $A \geqslant B>0$ ensures $A^{1+r-t} \geqslant\left\{A^{\frac{r}{2}}\left(A^{\frac{-t}{2}} B^{p} A^{\frac{-t}{2}}\right)^{s} A^{\frac{r}{s}}\right\}^{\frac{1+r-t}{(p-t) s+r}}$ for $t \in[0,1]$, $r \geqslant t, p \geqslant 1, s \geqslant 1$ and related inequalities, Arch. Inequal. Appl., 2 (2004), 141-157.

[26] T. FURUTA, Invitation to Linear Operators - From Matrices to Bounded Linear Operators on a Hilbert Space, Taylor \& Francis, London, 2001.

[27] T. FuRUTA, T. YAMAZAKI AND M. YANAGIDA, On a conjecture related to Furuta type inequalities with negative powers, Nihonkai Math. J., 9 (1998), 213-218.

[28] T. FurutA, T. YAMAZAKI AND M. YANAGIDA, Operator functions implying generalized Furuta inequality, Math. Inequal. Appl., 1 (1998), 123-130.

[29] M. ITO AND T. YAMAZAKI, Relations between two inequalities $\left(B^{\frac{r}{2}} A^{p} B^{\frac{r}{2}}\right)^{\frac{r}{p+r}} \geqslant B^{r}$ and $\left(A^{\frac{p}{2}} B^{r} A^{\frac{p}{2}}\right)^{\frac{p}{p+r}} \leqslant A^{p}$ and its applications, Integral Equations Operator Theory, 44 (2002), 442450 .

[30] J. F. JIANG, E. KAMEI AND M. FUJII, The monotonicity of operator functions associated with the Furuta inequality, Math. Japon., 46 (1997), 337-343.

[31] J. F. JIANG, E. KAMEI AND M. FUJII, Operator functions associated with the grand Furuta inequality, Math. Inequal. Appl., 2 (1998), 267-277.

[32] E. KAMEI, A satellite to Furuta's inequality, Math. Japon., 33 (1988), 883-886.

[33] E. KAMEI, Complements to the Furuta inequality II, Math. Japon., 45 (1997), 15-23.

[34] E. KAMEI, Parametrization of the Furuta inequality, Math. Japon., 49 (1999), 65-71.

[35] F. Kubo And T. Ando, Means of positive linear operators, Math. Ann., 246 (1980), $205-224$.

[36] K. TANAHASHI, Best possibility of Furuta inequality, Proc. Amer. Math. Soc., 124 (1996), 141-146.

[37] K. TANAHASHI, The Furuta inequality with negative powers, Proc. Amer. Math. Soc., 127 (1999), 1683-1692.

[38] K. TANAHASHI, The best possibility of the grand Furuta inequality, Proc. Amer. Math. Soc., 128 (2000), 511-519.

[39] T. YAMAZAKI, Extensions of the results on p-hyponormal and log -hyponormal operators by Aluthge and Wang, SUT J. Math., 35 (1999), 139-148.

[40] T. YAMAZAKI, Simplified proof of Tanahashi's result on the best possibility of generalized Furuta inequality, Math. Inequal. Appl., 2 (1999), 473-477.

[41] M. YANAGIDA, Powers of class $w A(s, t)$ operators associated with generalized Aluthge transformation, J. Inequal. Appl., 7 (2) (2002), 143-168.

[42] C. YANG AND J. YUAN, Extensions of the results on powers of p-hyponormal and log -hyponormal operators, J. Inequal. Appl., 2006 (2006), Article ID 36919, 1-14.

[43] C. Yang And J. Yuan, On class $w F(p, r, q)$ operators, Acta Math. Sci. Ser. A Chin. Ed., 27(5) (2007), 769-780.

[44] C. YANG AND H. ZUO, On the best monotone interval of function $F(\alpha)=\left(A^{r} B^{\alpha} A^{r}\right)^{(p+2 r) /(\alpha+2 r)}$, Acta Math. Sinica (Chin. Ser.), 47 (2004), 79-86.

[45] T. YosHINO, Introduction to operator theory, Longman Scientific and Technical, 1993.

[46] J. YUAN AND Z. GAO, The Furuta inequality and Furuta type operator functions under chaotic order, Acta Sci. Math. (Szeged), to appear.

[47] J. YUAN AND Z. GAO, Structure on powers of p-hyponormal and log-hyponormal operators, Integral Equations Operator Theory, to appear.

[48] J. YuAn AND C. YANG, Powers of class $w F(p, r, q)$ operators, JIPAM. J. Inequal. Pure Appl. Math., 7 (1) (2006), Article 32, 1-9. 